\title{
Hubungan antara Dukungan Keluarga dengan Kepatuhan Konsumsi Tablet Fe pada Ibu Hamil di Wilayah Kerja Puskesmas Nanggalo Kecamatan Nanggalo
}

\author{
Esthika Ariany Maisa ${ }^{a}$, Nelwati $^{a}$, Meri Neherta ${ }^{a}$ \\ ${ }^{a}$ Program Studi Ilmu Keperawatan Fakultas Kedokteran Universitas Andalas
}

\begin{abstract}
The low adherence of pregnant women in consuming Fe tablets is regarded to be the main cause of the ineffectiveness of Fe suplementation program held by the government to overcome anemia issue on pregnancy. One of the factor that influence the adherence of pregnant women is family support. This research was aimed at finding out the relationship between family support and the adherence in consuming Fe tablets among pregnant women in Puskesmas Nanggalo Kecamatan Nanggalo, Padang, West Sumatra in 2010. This research was designed in correlation study with a cross sectional approach and 32 respondents. Respondents were they who had got Fe tablets in her last visit from Puskesmas and also had health history with anemia in pregnancy. The data was collected by using questionnaire. Univariat and bivariat analysis were done to variable family support as well as the adherence of pregnant women. Bivariat analysis was done by cross tabulation with ChiSquare test. The result of the research showed that 54,9\% respondents got low family support and $71,9 \%$ respondents had low adherence in consuming Fe tablets. From the statistics experiment, it can be concluded that there is relationship between family support and women's adherence in consuming Fe tablets $(p<0.05)$. Therefore, it is suggested that nurses or another health worker in order to start asking and taking the family members, especially for husbands to join treatment toward pregnant women with anemia.
\end{abstract}

Keywords: Fe tablets, pregnant women's adherence, family support

\begin{abstract}
Abstrak : Kepatuhan yang rendah terhadap konsumsi tablet Fe pada ibu hamil dinilai sebagai penyebab utama tidak efektifnya program suplementasi Fe yang dibuat pemerintah untuk mengatasi masalah anemia dalam kehamilan. Salah satu faktor yang mempengaruhi kepatuhan ibu yaitu dukungan keluarga. Tujuan dari penelitian ini adalah untuk mengetahui hubungan dukungan keluarga dengan kepatuhan konsumsi tablet Fe pada ibu hamil di Puskesmas Nanggalo Kecamatan Nanggalo Kota Padang tahun 2010. Jenis penelitian adalah korelasi dengan pendekatan cross sectional dan responden sebanyak 32 orang. Responden yaitu ibu hamil yang telah mendapatkan tablet Fe dari Puskesmas pada kunjungan sebelumnya serta memiliki riwayat anemia selama kehamilan. Data dikumpulkan menggunakan kuesioner. Dilakukan analisa univariat dan bivariat terhadap variabel dukungan keluarga dan kepatuhan ibu hamil terhadap konsumsi tablet Fe. Analisa bivariat dilakukan dengan menggunakan uji statistik Chi-Square. Hasil penelitian menunjukkan sebanyak 59.4\% responden mendapat dukungan keluarga yang rendah dan $71.9 \%$ responden memiliki kepatuhan konsumsi tablet $\mathrm{Fe}$ yang rendah. Dari uji statistik dapat disimpulkan terdapat hubungan antara dukungan keluarga dengan kepatuhan konsumsi tablet $\mathrm{Fe}$ pada ibu hamil $(\mathrm{p}<0.05)$. Untuk itu, disarankan kepada perawat atau petugas kesehatan lainnya agar mulai mengajak dan mengikutsertakan anggota keluarga, terutama suami, dalam memberikan perawatan kesehatan bagi ibu hamil dengan anemia.
\end{abstract}

Kata Kunci: tablet Fe, kepatuhan ibu hamil, dukungan keluarga 
Dalam proses kehamilan, volume darah ibu dan eritropoesis meningkat secara fisiologik, namun penambahan volume plasma jauh lebih besar, sehingga konsentrasi hemoglobin $(\mathrm{Hb})$ dalam darah menjadi rendah. Fenomena ini dikenal sebagai anemia fisiologis (Bobak, Lowdermilk, \& Jensen, 2005). Kebutuhan zat besi (Fe) pada ibu hamil juga meningkat dibandingkan sebelum hamil (Arisman, 2010). Sementara $\mathrm{Fe}$ adalah nutrien yang tidak dapat diperoleh dalam jumlah yang adekuat dari makanan (Bobak dkk., 2005). Oleh karena itu, anemia pada kehamilan sering disebut anemia defisiensi besi (Manuaba, 1998).

Anemia defisiensi besi merupakan penyebab penting kematian ibu pada waktu melahirkan, maupun pada saat nifas sebagai akibat komplikasi kehamilan (Arisman, 1993, dikutip dari Rasmaliah, 2004). Anemia pada saat hamil juga akan mempengaruhi pertumbuhan janin, mengakibatkan berat bayi lahir rendah, dan peningkatan kematian perinatal.

Angka prevalensi anemia ibu hamil di Indonesia masih tinggi, berada pada kisaran 46\% - 92\% (Bakta, 2007). Untuk mengatasi masalah ini, pemerintah melalui Departeman Kesehatan (Depkes) RI sejak tahun 1970 telah mendistribusikan tablet besi (Depkes RI, 1996). Suplementasi tablet Fe dinilai sebagai cara yang efisien untuk mencegah dan mengobati anemia kurang besi karena kandungan besinya padat dan dilengkapi dengan asam folat. Tablet Fe diberikan secara gratis di Puskesmas, Puskesmas Pembantu, Posyandu, dan Bidan Desa di seluruh Indonesia.

Melalui program pemberian tablet besi ini, diharapkan dapat menurunkan angka kejadian anemia pada ibu hamil di Indonesia. Namun ternyata hasilnya belum begitu memuaskan, terlihat dari angka prevalensi yang masih tinggi. Rendahnya tingkat kepatuhan ibu hamil dalam mengkonsumsi suplemen besi merupakan salah satu penyebabnya (Purwaningsih, dkk., 2004).

Niven (2002) menyebutkan bahwa salah satu faktor yang dapat mempengaruhi kepatuhan penderita dalam menjalani program pengobatan adalah dukungan keluarga. Telah banyak dilakukan studi faktor-faktor lain, namun belum ada studi mengenai hubungan dukungan keluarga dengan kepatuhan minum tablet besi pada ibu hamil.

Dinas Kesehatan Kota (DKK) Padang mencatat sekitar 28,64\% dari 5.021 ibu hamil yang diperiksa $\mathrm{Hb}$ menderita anemia (Laporan Tahunan DKK Padang, 2009). Dalam memberikan pelayanan kesehatan kepada masyarakat, Kota Padang didukung oleh 20 unit puskesmas. Salah satunya adalah Puskesmas Nanggalo, puskesmas rawatan yang terletak di Kecamatan Nanggalo yang menyediakan layanan klinik bersalin 24 jam. Dibandingkan puskesmas lain, Puskesmas Nanggalo memiliki peningkatan angka kejadian anemia ibu hamil paling besar dari tahun 2008 hingga tahun 2009. Anemia ibu hamil juga termasuk masalah utama Kesehatan Ibu dan Anak (KIA) yang ada di Puskesmas Nanggalo Padang (Laporan Tahunan KIA Puskesmas Nanggalo, 2009). Dengan alasan itu maka peneliti memutuskan menjadikan puskesmas ini sebagai tempat penelitian.

Dari studi pendahuluan yang dilakukan peneliti pada tanggal 8 April 2010, didapat keterangan dari salah seorang perawat KIA Puskesmas Nanggalo bahwa pada kedatangan pertama ke puskesmas, setiap ibu diberikan 1 bungkus suplemen berisi 30 butir tablet Fe untuk dikonsumsi selama 1 bulan (1 butir/hari). Jika pada kunjungan selanjutnya tablet sudah habis, ibu akan diberikan lagi tablet dengan jumlah yang sama (Komunikasi interpersonal, 6 Agustus 2010).

Berdasarkan wawancara singkat peneliti kepada 10 orang ibu yang sudah 
mendapatkan tablet Fe dari Puskesmas, 4 diantaranya mengaku patuh meminum tablet Fe. Sisanya mengaku jarang, karena alasan lupa, susah buang air besar, lebih memilih makanan alami seperti buah atau sayur, serta ada yang hanya minum tablet jika merasa tidak enak badan. Ketika ditanya lebih lanjut, 3 orang ibu yang mengaku patuh minum tablet menjawab mendapat cukup dukungan keluarga, dari suami, orang tua, saudara ataupun anggota keluarga yang lain. Ibu mengaku diingatkan untuk minum tablet Fe. 2 orang suami yang berada ditempat wawancara mengaku mengingatkan istri untuk meminum tablet demi kesehatan istri dan calon bayi mereka. Sementara itu, 7 ibu lainnya mengaku kurang mendapat dukungan dari keluarga (Komunikasi interpersonal, 6 Agustus 2010).

Tekhnik sampling yang digunakan adalah non-random (non-probability) sampling, yaitu dengan cara purposive sampling (Notoatmodjo, 2005). Pengambilan sampel didasarkan pada pertimbangan tertentu yang dibuat oleh peneliti, yang diambil hanya sampel yang memenuhi kriteria inklusi, yaitu ibu hamil yang memiliki riwayat anemia. Dengan pertimbangan kepatuhan akan dipengaruhi oleh status anemik ibu hamil. Populasi pada penelitian ini adalah ibu hamil yang memeriksakan kandungannya dalam tiga bulan terakhir ke Puskesmas Nanggalo Padang. Jumlah populasi adalah 117 orang ibu hamil. Pada penelitian ini, didapatkan 32 orang sampel yang memenuhi kriteria, yang kemudian dijadikan responden penelitian.

Instrumen penelitian yang digunakan adalah kuisioner. Untuk menilai kepatuhan konsumsi tablet $\mathrm{Fe}$ ibu hamil digunakan Modified Morisky Scale, sedangkan untuk mengetahui dukungan keluarga yang dinilai oleh ibu digunakan kuisioner dengan skala Likert.

Analisa hubungan kedua variabel yang diduga berhubungan/berkorelasi antara
Berdasarkan latar belakang di atas, maka dapat dirumuskan masalah penelitian yaitu bagaimana hubungan antara dukungan keluarga dengan kepatuhan konsumsi tablet Fe pada ibu hamil di wilayah kerja Puskesmas Nanggalo Kecamatan Nanggalo Kota Padang tahun 2010?

\section{METODE}

Jenis penelitian yaitu korelasi dengan pendekatan cross sectional untuk mengetahui hubungan antara dukungan keluarga dengan kepatuhan konsumsi tablet Fe pada ibu hamil di Puskesmas Nanggalo Kota Padang Tahun 2010. Penelitian dimulai sejak bulan Maret s.d Desember 2010. Pengumpulan data dilakukan selama 2 minggu, dari tanggal 20 Oktober s.d 3 November 2010.

dukungan keluarga dengan kepatuhan konsumsi tablet $\mathrm{Fe}$ ibu hamil, digunakan uji hipotesis kategorik-kategorik, yaitu uji Kai-Kuadrat (Chi-Square).

\section{HASIL DAN PEMBAHASAN}

Berdasarkan hasil analisa bivariat didapatkan gambaran seperti ditampilkan pada tabel berikut:

Tabel 1. Hubungan Dukungan Keluarga dengan Kepatuhan Konsumsi Tablet Fe pada Ibu Hamil di Puskesmas Nanggalo Kota Padang

\begin{tabular}{|c|c|c|c|c|c|c|c|}
\hline \multirow{3}{*}{$\begin{array}{c}\text { Duku- } \\
\text { ngan } \\
\text { Keluarga }\end{array}$} & \multicolumn{4}{|c|}{ Kepatuhan Ibu } & \multirow{2}{*}{\multicolumn{2}{|c|}{ Total }} & \multirow{3}{*}{$\begin{array}{c}\mathrm{p} \\
\text { value }\end{array}$} \\
\hline & \multicolumn{2}{|c|}{ Penuh } & \multicolumn{2}{|c|}{ Rendah } & & & \\
\hline & $\mathrm{n}$ & $\%$ & $\mathrm{n}$ & $\%$ & $\mathrm{n}$ & $\%$ & \\
\hline Tinggi & 8 & 61,5 & 5 & 38,5 & 13 & 100 & \multirow{3}{*}{0,001} \\
\hline Rendah & 1 & 5,3 & $\begin{array}{l}1 \\
8\end{array}$ & 94,7 & 19 & 100 & \\
\hline Jumlah & 9 & 28,1 & $\begin{array}{l}2 \\
3\end{array}$ & 71,9 & 32 & 100 & \\
\hline
\end{tabular}

Hasil analisis hubungan antara dukungan keluarga dengan kepatuhan ibu hamil dalam mengkonsumsi tablet $\mathrm{Fe}$ diperoleh bahwa ada sebanyak 8 (61,5\%) ibu 
dengan dukungan keluarga yang tinggi mempunyai kepatuhan konsumsi penuh. Sedangkan diantara ibu dengan dukungan keluarga rendah, hanya $1(5,3 \%)$ yang mempunyai kepatuhan yang penuh. Berdasarkan hasil uji statistik Chi-Square yang dilakukan terhadap penelitian ini didapatkan nilai $\mathrm{p}=0,001 \quad(\mathrm{p}<0,05)$ sehingga hipotesis

penelitian yang menyatakan adanya hubungan antara dukungan keluarga dengan kepatuhan konsumsi tablet $\mathrm{Fe}$ pada ibu hamil, dapat diterima. Dari hal ini kemudian dapat diasumsikan bahwa peran keluarga sangatlah dibutuhkan oleh seseorang yang sedang menjalani program pengobatan (ada hubungan antara dukungan keluarga dengan kepatuhan ibu hamil dalam mengkonsumsi tablet $\mathrm{Fe}$ ).

Penelitian yang dilakukan oleh Hutapea (2008) menunjukkan bahwa penderita yang anggota keluarganya ikut memberikan dorongan selama proses pengobatan, menghasilkan penderita yang teratur minum obat setiap harinya. Sehingga dapat terlihat bahwa keluarga memang mempunyai peran yang sangat penting bagi kepatuhan seorang penderita untuk meminum obat.

Hasil penelitian mengenai hubungan dukungan keluarga dengan kepatuhan konsumsi tablet $\mathrm{Fe}$ pada ibu hamil menunjukkan bahwa dari 13 responden yang mendapatkan dukungan keluarga tinggi, lebih dari separuh $(61,5 \%)$ responden memiliki kepatuhan penuh terhadap konsumsi tablet Fe. Hasil ini sesuai dengan teori Force field analysis yang diungkapkan Lewis (dikutip dari Hutapea, 2008) bahwa agar perilaku penderita lebih patuh diperkuat dengan driving force dengan cara menggalakkan persuasi dan memberi informasi, yang dalam hal ini bisa didapatkan dari keluarga.

Namun, dari 13 responden yang mendapatkan dukungan keluarga tinggi tersebut, terdapat 5 responden $(38,5 \%)$ yang memiliki kepatuhan konsumsi tablet $\mathrm{Fe}$ yang rendah. Seperti yang telah diungkapkan sebelumnya, hal ini bisa terjadi karena faktor status kehamilan dan sikap yang dimiliki ibu hamil. Sebagian besar $(87,5 \%)$ responden yang merupakan ibu multigravida, seperti yang diungkapkan Jasti, dkk (2005), merupakan faktor yang berkemungkinan besar menjadi penyebab ketidakpatuhan ibu hamil pada penelitian ini. Selain itu, pemahaman ibu mengenai kebutuhan akan tablet Fe yang kurang atau tidak tepat juga dapat membuat ibu menganggap tablet $\mathrm{Fe}$ tidak begitu penting dan berpikiran bahwa anemia kehamilan bisa diatasi hanya dengan asupan sehari-hari saja. Hal ini sesuai dengan yang didapatkan Galloway, dkk (2000) dalam penelitiannya bahwa pemahaman yang kurang mengenai anemia merupakan faktor utama penyebab rendahnya konsumsi tablet $\mathrm{Fe}$ pada ibu hamil di Indonesia.

Sebaliknya, dari 19 responden yang mendapatkan dukungan keluarga rendah, hampir seluruhnya $(94,7 \%)$ memiliki kepatuhan konsumsi tablet $\mathrm{Fe}$ yang rendah. Sesuai dengan pernyataan Niven (2002) bahwa derajat dimana penderita tidak mendapat pendampingan dari orang terdekat seperti keluarga, berhubungan secara negatif dengan kepatuhan. Penderita yang tidak mendapat dukungan keluarga yang cukup akan sangat mungkin untuk tidak mematuhi program pengobatan yang diberikan kepadanya.

Adapun dari 23 responden yang mendapatkan dukungan keluarga rendah, sebagian kecil $(5,3 \%)$ responden memiliki kepatuhan konsumsi tablet Fe yang tinggi. Hal ini bisa disebabkan karena ibu memang telah memiliki pemahaman yang sangat baik mengenai perlunya ia mengkonsumsi tablet Fe selama kehamilan sehingga walaupun tanpa dukungan keluarga yang cukup ia tetap bisa memutuskan untuk mematuhi instruksi mengkonsumsi tablet Fe.

\section{KESIMPULAN DAN SARAN}

Berdasarkan hasil penelitian yang dilakukan tentang hubungan dukungan keluarga dengan kepatuhan konsumsi tablet Fe pada ibu hamil di wilayah kerja 
Puskesmas Nanggalo Kota Padang Tahun 2010, maka dapat diambil kesimpulan bahwa lebih dari separuh (59.4\%) ibu hamil di Puskesmas Nanggalo Kota Padang mendapat dukungan keluarga yang rendah, lebih dari separuh $(71.9 \%)$ ibu di hamil di Puskesmas Nanggalo Kota Padang memiliki kepatuhan konsumsi tablet Fe yang rendah, dan bahwa terdapat hubungan antara dukungan keluarga dengan kepatuhan konsumsi tablet $\mathrm{Fe}$ pada ibu hamil di Puskesmas Nanggalo Kota Padang $(\mathrm{p}<0,05)$.

Sehingga diharapkan petugas puskesmas ikut mengajak dan mengikutsertakan anggota keluarga, terutama suami, dalam memberikan perawatan kesehatan bagi ibu hamil. Anggota keluarga diberikan penjelasan yang cukup mengenai pentingya ibu untuk mengkonsumsi tablet $\mathrm{Fe}$ dan diminta partisipasinya dalam memberi perhatian dan perawatan bagi ibu selama masa kehamilan.

\section{DAFTAR PUSTAKA}

Arisman. (2010). Buku ajar ilmu gizi: Gizi dalam daur kehidupan, Edisi 2. Jakarta: EGC.

Bakta, I.M. (2007). Hematologi klinik ringkas. Jakarta: EGC.

Bobak, I.M., Lowdermilk, D.L., \& Jensen, M.D. (2005). Buku ajar keperawatan maternitas, Edisi 4. Jakarta: EGC

Degresi. (2005). Ilmu perilaku manusia. Jakarta: PT. Rineka Cipta.

Freedman, M.D. (2005). In a family way: Getting everyone involved. Diakses tanggal 21 November 2010 dari http://www.firstbabymall.com/ex pecting/pregnancy/family.htm.

Galloway, dkk. (2005). Women's perceptions of iron deficiency and anemia prevention and control in eight development countries. Diakses tanggal 24 November $2010 \quad$ dari http://pdf.usaid.gov/pdf_docs/PN ACL180.pdf.

Hutapea, T.P. (2008). Pengaruh dukungan keluarga terhadap kepatuhan minum obat anti tuberkulosis. Diakses tanggal 22 Juni 2010 dari

http://jurnalrespirologi.org/jurnal/ April09/Dukungan\%20Keluarga. pdf

Jasti, S., Siega-Riz, A.M., Cogswell, M.E., Hartzema, A.G., \& Bentley, M.E. (2005). Pill count adherence to prenatal multivitamin/ mineral supplement use among lowincome women. The Journal of Nutrition, 135(5), 1093-1102.

Manuaba, I.B.G. (1998). Ilmu kebidanan, penyakit kandungan \& keluarga berencana untuk pendidikan bidan. Jakarta: EGC.

Niven, N. (2002). Psikologi kesehatan: Pengantar untuk perawat dan profesional kesehatan lain. Jakarta: EGC.

Notoatmodjo, S. (2005). Metodologi penelitian kesehatan. Jakarta: Rineka Cipta.

Prawirohardjo, S. (2005). Ilmu kebidanan, Edisi Ketiga, Cetakan 7. Jakarta: Yayasan Bina Pustaka Sarwono Prawirohardjo

Proverawati, A. \& Asfuah, S. (2009). Buku ajar gizi untuk kebidanan. Yogyakarta: Nuha Medika.

Purwaningsih, M., Akhmadi, \& Artaty, W. (2006). Analisa faktor-faktor yang mempengaruhi ketidapatuhan ibu hamil dalam mengkonsumsi tablet besi. Jurnal Ilmu Keperawatan, 01(02), 72-81.

Rasmaliah. (2004). Anemia kurang besi dalam hubungannya dengan infeksi cacing pada ibu hamil. Diakses tanggal 10 Oktober 2010 
dari

http://library.usu.ac.id/download/f $\mathrm{km} / \mathrm{fkm}$-rasmaliah8.pdf.

Rigby, D. (2007). Adherence assessment tools: Drugs don't work when they're not taken. The Australian Journal of Pharmacy, 88, 32-33.
Saifuddin. (2002). Buku acuan: Asuhan persalinan normal. Jakarta.

Slamet B. (2007). Psikologi umum. Bandung: PT Remaja Rosdakarya.

Soebroto, I. (2009). Cara mudah mengatasi problem Anemia. Yogyakarta: 